\title{
Mundo Bit Byte: Um jogo digital para disseminar o conhecimento sobre personalidades femininas na Computação
}

\author{
Ana Júlia L. Briceño ${ }^{1}$, Ana Sofia S. Silvestre ${ }^{1}$, Bianca P. Castro ${ }^{2}$, \\ Hanani E. F. Soares ${ }^{1}$, Tais A. Oliveira ${ }^{1}$, Thamires P. Silva ${ }^{1}$, Aleteia P. F. Araujo ${ }^{1}$, \\ Carla D. Castanho ${ }^{1}$, Carla Cavalcante Koike ${ }^{1}$, Maristela Holanda ${ }^{1}$, Roberta B. Oliveira ${ }^{1}$ \\ ${ }^{1}$ Universidade de Brasília (UnB), Brasília - DF \\ ${ }^{2}$ Colégio Estadual Pedro Mourão, Cidade Ocidental - GO \\ \{ana.luziano, ana.silvestre, hanani.emanuelle, tais.oliveira, \\ thamires.pontes\}@aluno.unb.br, biancapatrocinio774@gmail.com, \\ \{aleteia, carlacastanho, mholanda, ckoike, roberta.oliveira\}@unb.br
}

\begin{abstract}
There are great female personalities in the history of computing who have played an important role in the historical achievements of this area. However, their contributions are often poorly publicized and/or the credits of those contributions are denied to the true authors. Thus, this paper proposes a game called Mundo Bit Byte, created by a team of undergraduate and high school girls. The story is based on five prominent female personalities in the field of Computing. Each phase of the game is inspired by the life of one of these women, showing, in a playful and fun way, their achievements and other relevant aspects of their lives. A demo version of the game containing the first phase was evaluated by 234 people of different educational levels, genders and age groups. The results indicated that the experience of the first phase of the game contributed to the knowledge and aroused the interest of the players in knowing more about female personalities in the history of computing.
\end{abstract}

Resumo. Há grandes personalidades femininas na história da computação que tiveram importante atuação nos feitos históricos desta área. Todavia, muitas vezes as suas contribuições são fracamente divulgadas elou os créditos dessas contribuições são negados às verdadeiras autoras. Assim, esse artigo propõe o jogo denominado Mundo Bit Byte, criado por um time de meninas de graduação e ensino médio, cuja temática e enredo são baseados em cinco personalidades femininas de destaque na área da Computação. Cada fase do jogo é inspirada na vida de uma dessas mulheres, mostrando, de uma forma lúdica e divertida, as conquistas e outros aspectos relevantes da trajetória da mulher tema da etapa. Uma versão demo do jogo contendo a primeira fase foi avaliada por 234 pessoas de diferentes níveis de escolaridade, gêneros e faixas etárias. Os resultados indicaram que a experiência com a primeira fase do jogo contribuiu para o conhecimento e despertou o interesse dos jogadores em conhecer mais sobre personalidades femininas na história da computação. 


\section{Introdução}

De acordo com o INEP (Instituto Nacional de Estudos e Pesquisas Educacionais Anísio Teixeira), em 2019 a porcentagem de pessoas do sexo feminino que concluíram a graduação na grande área da Computação e Tecnologias da Informação e Comunicação (TIC) foi de 13,6\% [INEP 2020]. Isso expõe a discrepância entre a quantidade de homens e mulheres que atuam na área da Computação. Entre os atores que influenciam o interesse de meninas e mulheres nas áreas que envolvem Ciência, Tecnologia, Engenharia e Matemática estão, o contato, a apresentação, a quebra de esteriótipos e os exemplos femininos que atuam na área [UNESCO 2018].

Esse contexto motivou a idealização do jogo digital denominado Mundo Bit Byte, o qual foi desenvolvido por seis alunas iniciantes em programação, sendo cinco delas de graduação da Universidade Brasília e uma da Escola Pública Colégio Estadual Pedro Mourão que integram o projeto de extensão Meninas.comp da Universidade de Brasília. O jogo Mundo Bit Byte tem como principal objetivo divulgar, de forma criativa e metafórica, características e feitos de cinco grandes personalidades femininas do mundo da Computação. Cada fase do jogo representa uma dessas mulheres e foi criada com objetos, frases e pensamentos das respectivas personalidades, incluindo cores, sons, inimigos e conquistas que as remetessem.

Assim, inicialmente foi lançada uma demonstração da primeira fase do jogo para aparelhos Android. Essa plataforma foi escolhida por ser a mais utilizada e também por motivos de acessibilidade, uma vez que o aparelho móvel de celular é o principal meio de acesso à Internet no Brasil [CETIC.BR 2020]. Além disso, vale destacar que o acesso à Internet é necessário apenas para instalar o jogo e não para jogá-lo em si.

Para apresentar o jogo Mundo Bit Byte, este artigo está composto, além desta seção, por mais quatro seções. A Seção 2 apresenta uma análise dos trabalhos relacionados. A Seção 3 traz uma descrição do jogo. Em seguida, a Seção 4 apresenta os resultados preliminares de avaliação do jogo, referentes à primeira fase. Por fim, a Seção 5 apresenta algumas considerações finais e os trabalhos futuros.

\section{Trabalhos Relacionados}

Em [Alencar et al. 2019] um jogo de cartas chamado Computasseia foi proposto para aprendizagem e memorização sobre grandes influências femininas na história da Computação. A avaliação do jogo foi realizada com 45 estudantes de escolas públicas e particulares, e universitárias. Contudo, é importante ressaltar que os jogadores tiveram que ser inicialmente submetidos a uma breve aula sobre a história da Computação, pois durante o jogo essa informação era necessária e a maioria dos avaliadores não possuía nenhum conhecimento sobre o tema.

Em [Angeli et al. 2020] foi apresentada uma proposta de construção de um jogo com estudantes do Ensino Fundamental II de uma escola pública por meio do Design Participativo. O jogo tem como função abordar as contribuições das mulheres para a Ciência, com o objetivo de proporcionar discussões sobre este assunto e trazer uma nova percepção nos jovens para o mundo da tecnologia. Todavia, o jogo proposto não estava pronto e o artigo foi dedicado a uma descrição teórica de como seriam feitas as pesquisas para levantamento dos dados. 
Em [Oliveira et al. 2019] foi descrito o jogo "Personalities"que tem como objetivo divulgar personalidades importantes porém pouco divulgada na área de Computação, assim como também a discussão de gênero. algumas personalidades do jogo estão, por exemplo, Ada Lovelance e Hedy Lamarr.

Em [Milson et al. 2020] um website que disponibiliza três mini-jogos criados com o objetivo de divulgar personagens femininas na Computação e nas Ciências foi apresentado. Este website, com o público-alvo estudantes do ensino médio, é um dos produtos do Projeto Bytes \& Elas, e foi desenvolvido por alunas do ensino médio do curso técnico integrado. Dentre os três mini-jogos, um deles denominado "Ajudando Marie" que tem como personagem principal Marie Curie, uma das cientistas mais conhecida por suas contribuições da radiatividade. Outro jogo chamado "Quem Sou Eu", cujo foco é fazer os jogadores desenvolverem maior conhecimento sobre mulheres que tiveram grande importância na Ciências. Por fim, implementou-se um Jogo de Memória, tendo como meta passar aos jogadores conhecimentos sobre seis mulheres importantes para a computação.

Diferentemente dos jogos apresentados nesta seção, o Mundo Bit Byte foi desenvolvido para a plataforma móvel Android, pode ser jogado sem um conhecimento prévio das histórias das personalidades femininas, e não é necessário estar conectado na Internet para poder jogar.

\section{Jogo Mundo Bit Byte}

O Mundo Bit Byte é um jogo desenvolvido para plataformas mobile, com o objetivo de difundir, principalmente, entre as meninas dos ensinos médio e fundamental, o conhecimento sobre importantes personalidades femininas da computação e, como consequência, incentivá-las a considerarem a área da Computação como uma possível alternativa profissional. Pois, ao notarem que há representatividade feminina na área, as meninas podem se sentir mais motivadas a seguirem carreira na área de TI.

O jogo foi criado por uma equipe composta por alunas dos ensinos superior e médio, e desenvolvido utilizando-se a engine Unity ${ }^{1}$ e a linguagem C\#. O código fonte está disponível no GitHub Mundo Bit Byte ${ }^{2}$. O objetivo do jogo é passar por 5 fases que buscam apresentar, de forma cômica e metafórica, características e feitos de grandes personalidades femininas do mundo da Computação. Cada fase foi criada com objetivos, frases e pensamentos dessas personalidades, incluindo cores, sons, inimigos e conquistas, conforme o Game Design Document ${ }^{3}$. A Figura 1 apresenta a tela inicial do jogo Mundo Bit Byte.

A estória desenvolvida no jogo começa no ano de 2121 em Labrisaí, uma cidade futurista com grandes campados, prédios baixos suspensos, ruas que lembram tesouras e acessos que lembram agulhas no eixo principal. Contudo, a narrativa desenvolvida no jogo não se prende a esse ano e cenário. Alienígenas misteriosos chegam ao planeta Terra, lançando um tipo de vírus que em contato com os seres humanos suga todo o conhecimento ligado à computação, quando tocam equipamentos eletrônicos invalidam estes. Como consequência da invasão, as pessoas esquecem como programar e todos os

\footnotetext{
${ }^{1}$ https://unity.com/pthttps://unity.com/pt

${ }^{2}$ https://github.com/meninas-comp-UnB/jogo.githttps://github.com/meninas-comp-UnB/jogo.git

${ }^{3}$ https://bityli.com/mundobitbytehttps://bityli.com/mundobitbyte
} 


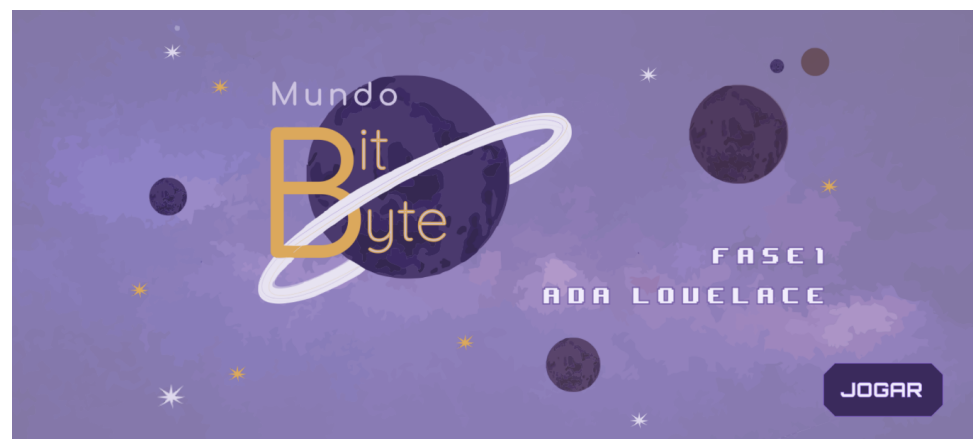

Figura 1. Tela inicial e menu do Jogo Mundo Bit Byte.

eletrônicos terrestres, são destruídos. Assim, as pessoas ficam sem celular, sem Internet, e até sem qualquer mecanismo que viabilize as pesquisas nas bases de dados virtuais.

Ram, um alienígena que se afeiçoou a um grupo de amigas humanas, tenta ajudálas, doando uma máquina do tempo pouco convencional, uma vez que ao viajar nela os aspectos físicos da época eram desconfigurados. Este grupo era composto por cinco garotas: Tati uma menina de 14 anos, muito corajosa e inventiva; Bell uma adolescente de 17 anos, apaixonada por cultura japonesa, filmes e café; Amélia uma jovem muito confiante e desastrada; Ema "uma deusa, uma louca, uma feiticeira"; Durga uma mulher descendente de indianos, cheia de mistérios; e Elaine uma senhora de 63 anos com cara de marrenta, mas bem fofa que descobre o seu amor por tecnologia ao procurar entretenimentos para sua neta. Elas eram hackers que estavam na Computeca (o local físico onde pessoas tinham acesso a livros virtuais), onde se encontravam semanalmente para estudar, compartilhar experiências e desenvolverem projetos juntas.

Acompanhadas de uma pequena invenção delas, um robô chamado Turing - que armazenava um grande volume de dados mas não conseguia processá-los - elas viajam no passado com a missão de recuperar os 5 pilares importantes para o grupo (algoritmo, diversão, simplicidade, persistência e comunicação), antes que os alienígenas acabem com a humanidade. Nesse cenário, o Mundo Bit Byte se desenvolve em 5 fases, sendo cada fase dedicada a apresentar uma personagem histórica da área de computação. Essas fases serão descritas nas próximas seções.

\subsection{Fases do Jogo}

Cada fase do jogo representa e tem sua temática baseada em uma das seguintes personalidades da computação: Ada Lovelace, Carol Shaw, Susan Kare, Grace Hopper e Hedy Lamarr. Elas trazem uma identidade visual única e um quebra-cabeça específico, que quando concluído a personagem ganha vidas extras. Além disso, se o jogador tiver coletado todos os objetos colecionáveis da fase, ele conquista um objeto especial daquela etapa do jogo. Para representar a evolução do conhecimento adquirido em cada fase, a interface gráfica vai ficando mais definida. Assim sendo, o jogo inicia-se com Tati. Todavia, a cada etapa diferentes personagens são desbloqueadas, tornando assim a experiência do usuário mais interativa e interessante. Ao final da quinta fase o jogador conclui todo o enredo.

Trata-se de um jogo do gênero Plataforma [Rabin 2009], portanto a jogabilidade consiste em superar os obstáculos como rampas, plataformas que se movimentam, bura- 
cos, espinhos, pontes que caem, visibilidade restrita, inimigos que andam pelo cenário ou que atiram objetos entre outros, podendo apenas pular, se movimentar para os lados e atacar.

\subsubsection{Primeira fase}

Fase criada para homenagear Ada Lovelace, que é conhecida por ter construído o primeiro algoritmo computacional. O cenário da fase é em Londres nos anos 1840 . O quebracabeça desta fase é relacionado com matemática, por Ada ter se formado em matemática, e o objeto colecionável desta etapa são argolas de um ábaco. Os inimigos são representados por cavalos de corrida, pois Ada gostava desse esporte apesar de perder dinheiro nas apostas ${ }^{4}$. Outro inimigo nesta fase é o cavalo com asas, pois Ada acreditava que podia criar um mecanismo capaz de voar, e ele teria forma de um cavalo alado, conforme apresentado na Figura 2.

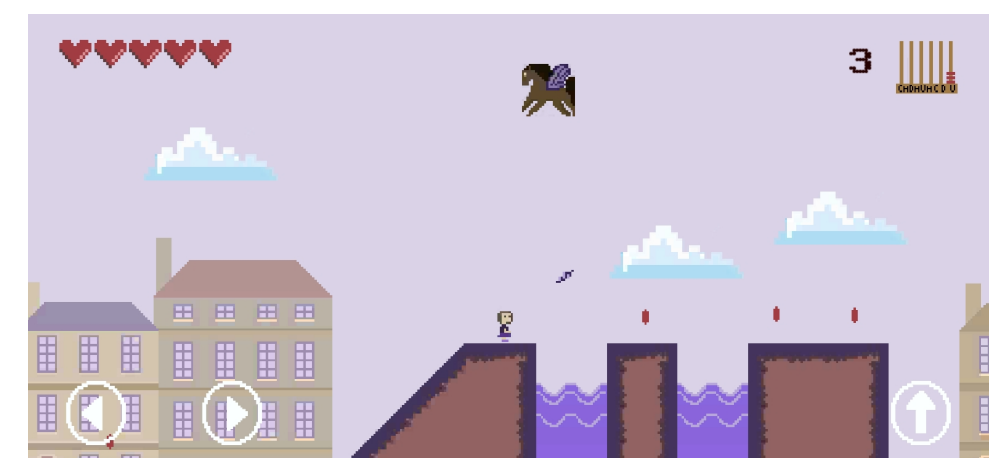

Figura 2. Imagem da primeira fase da demo.

\subsubsection{Segunda fase}

Fase criada para homenagear Carol Shaw que é reconhecida por ser a primeira mulher desenvolvedora de jogos. A fase se passa em Palo Alto na década de 70. O quebracabeça desta fase é relacionado ao jogo Tic-Tac-Toe 3D criado por Carol Shaw ${ }^{5}$. O objeto colecionável é a quantidade de gasolina, em referência ao jogo mais famoso dela chamado River Raid ${ }^{6}$. O grande desafio da fase é o ambiente noturno, no qual o jogador terá uma visibilidade restrita, contando apenas com a luz de uma lanterna que deverá coletar bateria para seu funcionamento. A noite foi escolhida como inimigo porque Carol Shaw costumava ser rigorosa com seus horários de trabalho, uma vez que frequentemente ia trabalhar de bicicleta e não gostava de voltar para casa tarde.

\footnotetext{
${ }^{4}$ Marília Marasciulo: https://www.bbc.com/portuguese/internacional-54017008

${ }^{5}$ Wikipedia: 3D tic-tac-toe: https://en.wikipedia.org/wiki/3D_tic-tac-toe

${ }^{6}$ Wikipedia: River Raid: https://en.wikipedia.org/wiki/River_Raid
} 


\subsubsection{Terceira fase}

Fase criada para homenagear Susan Kare, a designer gráfica responsável por trazer um aspecto mais amigável aos computadores. Susan Kare foi a criadora das interfaces gráficas e dos ícones do sistema operacional do Apple Macintosh, o Mac OS, original de 1984. O cenário da fase é a cidade de Nova York dos anos 1980. O objeto colecionável desta fase são pequenos pontos que podem ser tanto da cor preta quanto branca, que no final irão compor a imagem dela, representando os pixels tão comuns à artista. O quebra-cabeça também fará a mesma referência, sendo um Nanograma ${ }^{7}$ de um caju mordido, alusão à famosa maçã da Apple, e que simboliza grande parte da trajetória profissional da ilustradora. Os inimigos são cartas de baralho que lançam flechas ou atacam com machados, em referência ao primeiro jogo de paciência do sistema operacional Windows, criado em 1990, do qual Susan fez o design das cartas.

\subsubsection{Quarta fase}

Esta fase foi planejada para homenagear Grace Murray Hopper que foi a criadora do primeiro compilador. O cenário desta fase se passa em um navio, pois ela foi almirante e analista de sistemas da marinha dos Estados Unidos. Assim sendo, o quebra-cabeça desta fase será um enigma a ser decifrado, e nele haverá um texto com letras destacadas no qual o jogador deverá formar uma frase. Esse quebra-cabeça faz alusão à tradução da linguagem natural para linguagem de máquinas realizada pelos compiladores. Os objetos colecionáveis desta fase serão diplomas, pois Grace Hopper recebeu 40 diplomas honorários ${ }^{8}$. Os inimigos desta fase serão fantasmas e insetos. Os fantasmas foram adotados para fazer referência ao avô dela que a inspirou entrar na marinha. Os insetos foram implementados uma vez que foi atribuído a ela a origem do termo " $b u g$ ", , termo coloquial usado para designar erros em um software.

\subsubsection{Quinta fase}

A quinta fase do jogo Mundo Bit Byte foi criada para homenagear Hedy Lamarr, pois ela é considerada a mãe da telefonia celular e do Wifi ${ }^{10}$. Esta fase se passa em um estúdio de cinema, uma vez que em vida, ela foi uma grande atriz. O quebra-cabeça será um jogo de ritmo, no qual o jogador deverá pressionar o botão quando uma onda estiver na posição correta, referência as 88 diferentes frequências que Hedy Lamar sugeriu para despistar os radares durante a Segunda Guerra Mundial. Os objetos colecionáveis escolhido para esta fase são estrelas, fazendo analogia à calçada da fama na qual a atriz está representada. Os inimigos são um príncipe que atira maçãs, além de espelhos e quadros que quebram e causam danos. Eles simbolizam a beleza da atriz, sendo que o primeiro é também uma menção a animação da Branca de Neve produzida pela Disney no qual a aparência da princesa foi inspirada em Hedy Lammar.

\footnotetext{
${ }^{7}$ Wikipedia: Nonogram: https://en.wikipedia.org/wiki/Nonogram

${ }^{8}$ Wikipedia: Grace Hopper: https://pt.wikipedia.org/wiki/Grace_Hopper

${ }^{9}$ National Geographic: https://www.nationalgeographic.org/thisday/sep9/worlds-first-computer-bug/

${ }^{10}$ Marília Marasciulo: https://www.bbc.com/portuguese/internacional-54017008
} 


\section{Resultados Preliminares}

Com o objetivo de conduzir uma avaliação preliminar do jogo Mundo Bit Byte foi disponibilizada na Play Store uma versão de demonstração, também popularmente chamada de "demo", contendo a primeira fase do jogo, cuja temática é destinada a Ada Lovelace. Os testes preliminares tiveram o objetivo de avaliar, dentre outros aspectos a jogabilidade, a aceitação e o interesse em conhecer mais figuras femininas importantes na computação. A demo teve 480 downloads em um período de apenas 7 dias. Nessa versão do jogo o público teve acesso ao cenário e inimigos da Fase 1, além dos controladores de movimentação lateral e vertical.

A avaliação da experiência dos jogadores foi realizada por meio de um formulário Google. Assim, participaram da pesquisa pessoas de diferentes faixas etárias, níveis de escolaridade, gênero e perfil de jogadores. No total foram obtidas 234 respostas, dentre as quais, $39,7 \%$ se identificaram como do gênero feminino, $56,8 \%$ do gênero masculino, $3,4 \%$ como outros.

Além disso, dos 234 jogadores, $0,4 \%$ era da faixa etária até 10 anos, 5,6\% tem idade de 11 a 14 anos, 29,5\% tem de 15 a 18 anos, $41 \%$ apresentou uma faixa etária de 19 a 25 anos, 20,1\% tem 26 a 40 anos, 3\% tem de 41 a 60 anos e outra parte de $0,4 \%$ está acima de 61 anos, conforme mostrado na Figura 3. Em relação à escolaridade dos jogadores, $7,7 \%$ dos respondentes relataram estar no ensino fundamental, 36,3\% no ensino médio e 56\% no ensino superior, conforme apresentado na Figura 4. Quando perguntado sobre o hábito de jogar, 47,9\% responderam que jogam bastante, 34,6\% que jogam eventualmente e 17,9\% não têm o hábito de jogar (Figura 5).

Assim sendo, nota-se que o perfil predominante dos respondentes é formado por homens que têm entre 18 e 25 anos, que se caracterizaram como sendo pessoas que jogam bastante e cursam o ensino superior. Tal perfil justifica-se pelo fato da divulgação ter ocorrido predominantemente no ambiente universitário dos cursos de computação que são majoritariamente masculinos. Acredita-se que a identificação deste perfil é relevante para este estudo, já que a análise das respostas mostra que, em sua maioria, as pessoas que responderam estão bastante familiarizadas ao mundo dos jogos digitais.

No intuito de identificar a eficácia do jogo no que diz respeito ao seu objetivo principal, que é promover a divulgação de importantes personalidades femininas da história da computação, foi perguntado se o jogador conhecia, antes de jogar, a personalidade feminina principal da primeira fase do jogo Mundo Bit Byte, Ada Lovelace. Nesse caso, 67,52\% de todos os respondentes declararam não a conhecer (Figura 6), e 69,9\% do público especificamente feminino também não sabia quem era Ada (Figura 7). Todavia, conforme apresentado na Figura 8, 97,44\% dos participantes responderam que têm interesse em conhecer novas figuras femininas importantes da área da computação. Portanto, conclui-se que o jogo Mundo Bit Byte cumpriu a sua missão de fazer com que mais meninas conheçam e tenham interesse em conhecer as personalidades femininas na Computação. Contudo, além deste resultado direto, notou-se um interesse do público masculino em conhecer as personagens femininas da computação também. Isso é interessante ser observado, pois mostra que os meninos devem ser despertados para o apoio de mais mulheres na área. Assim sendo, as ações que incentivam maior atuação feminina também podem ser voltadas para atividades que despertem o interesse dos meninos. 
O formulário usado para coletar dados sobre o jogo incluía perguntas sobre questões de gênero. A Figura 9 expõe os resultados percentuais da pergunta "Você acha que o jogo é destinado a um público específico?", a maioria dos respondentes marcou a opção "Não". Para os que marcaram "Sim"foi perguntado a qual tipo de grupo o jogo seria destinado, e as respostas podem ser observadas na Figura 10, na qual somente 7,69\% das pessoas responderam que é para o público feminino, mostrando assim que a temática apresentada não é limitada apenas ao público feminino. Outro aspecto que frequentemente está relacionado a gênero é a paleta de cores. Para isso foi perguntado no formulário sobre a percepção da paleta de cores, e $18,53 \%$ responderam que a acharam feminina, $0,86 \%$ pensaram ser masculina, $73,71 \%$ não viram distinção e $6,9 \%$ acharam positiva. A maioria dos respondentes afirmou que não houve distinção de gênero, logo para o usuário o jogo é tido como neutro e destinado a todos os gêneros. Este resultado é considerado como uma avaliação positiva, pois mostra que as meninas podem desenvolver tecnologia que agrade a todos, e não somente ao público feminino, como pode ser visto na Figura 11. Por fim, a nota que os respondentes deram ao jogo foi positiva (Figura 12), da qual a média da nota igual a 8,15 para o jogo.

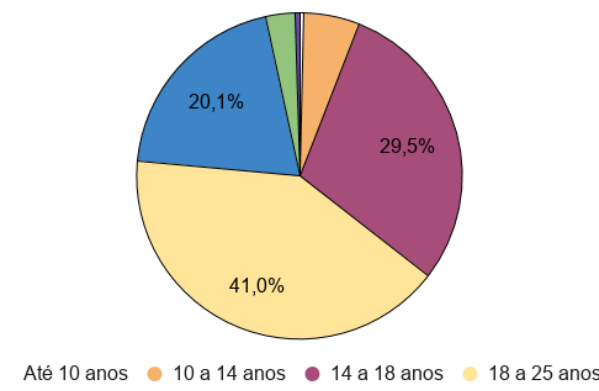

- 25 a 40 anos 40 a 60 anos Mais que 60 anos

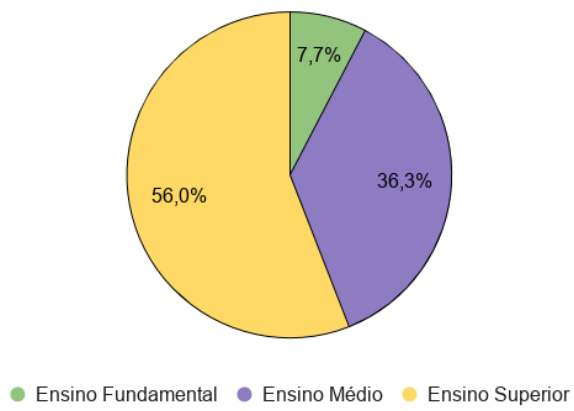

Figura 4. Nível de escolaridade.

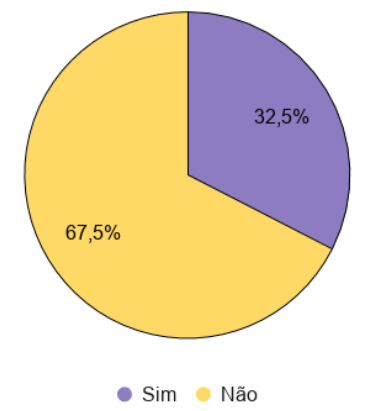

- Que joga bastante Que joga eventualmente Não tem hábito de jogar

Figura 5. Você tem hábito de jogar?

Figura 6. Você conhecia Ada Lovelace antes do jogo? Porcentagem em relação ao público geral. 


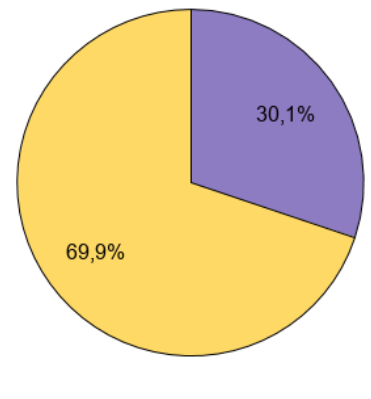

- Conhece Não conhece

Figura 7. Você conhecia Ada Lovelace antes do jogo? Porcentagem em relação ao público feminino.

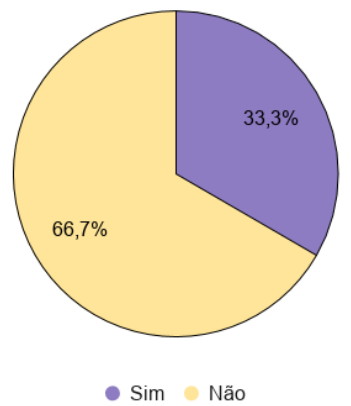

Figura 9. Você acha que esse jogo é destinado a um público específico?

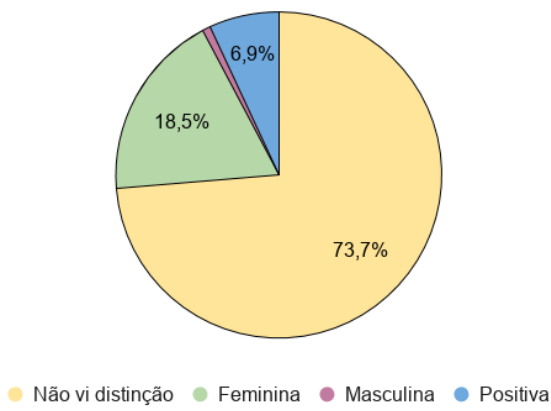

Figura 11. O que você achou da paleta de cores?

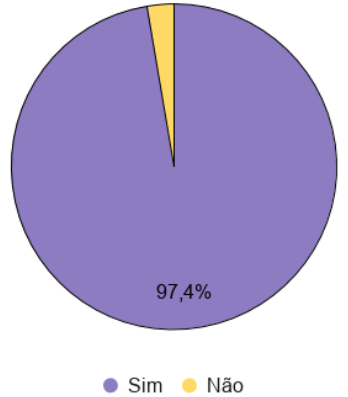

Figura 8. Você gostaria de conhecer outras mulheres importantes da computação? Porcentagem em relação ao público geral.

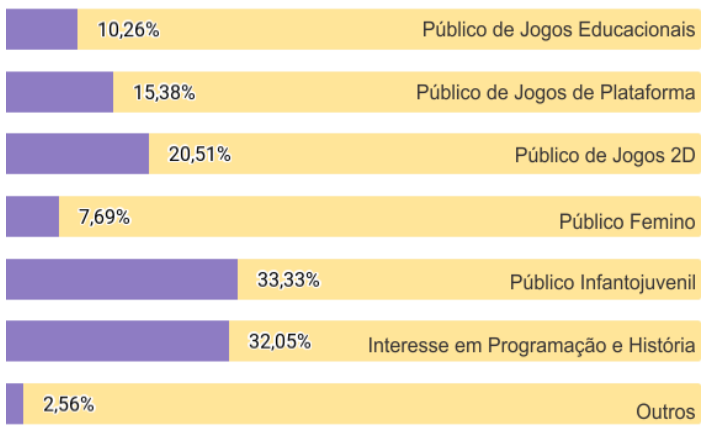

Figura 10. Se sim, a qual público você acha que ele é destinado?

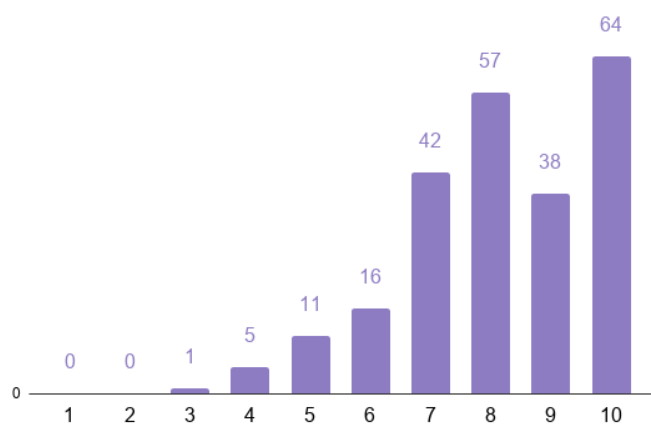

Figura 12. De 0 a 10 que nota você daria ao jogo? 


\section{Considerações Finais e Trabalhos Futuros}

Este artigo apresentou Mundo Bit Byte, que está sendo construído por mulheres, cujo objetivo é despertar a curiosidade sobre personalidades femininas na área de computação. Contudo, este jogo, até o momento, não é percebido como específico para o público feminino, e isso foi ratificado pela análise dos resultados da pesquisa realizada a respeito da primeira fase, mesmo considerando que o maior grupo de jogadores tenha sido identificado como homens que costumam jogar bastante. Isso é positivo porque mostra que o mundo dos jogos digitais não tem gênero, e que tanto as meninas quanto os meninos podem atuar nesta área.

O jogo Mundo Bit Byte é um projeto ambicioso, que está em desenvolvimento e que objetiva ser uma ferramenta que auxilie a divulgação da área de computação, enquanto pretende mostrar para a sociedade que computação também é feita por mulheres. Assim, visto que a versão publicada é uma demonstração, existem muitas funcionalidades que devem ser acrescentadas para a conclusão deste jogo. Como trabalhos futuros, pretende-se melhorar a Fase 1 a partir das contribuições recebidas com a avaliação feita, e finalizar todas as próximas 4 fases restantes. Além disso, pretende-se disponibilizar o jogo também na plataforma iOS.

\section{Referências}

Alencar, A. I., Pinheiro, V. M., and Marques, A. B. (2019). Promovendo o conhecimento sobre mulheres na Computação: experiência com o jogo de cartas Computasseia no ensino de História da Computação. 2019: Anais do XIII WIT, 13:139-143.

Angeli, S., Gasparini, I., and Bim, S. A. (2020). Colocando as cartas na mesa: apresentando as Mulheres na Ciência por meio de um jogo. 2020: Anais do XIV WIT, 14:184-188.

CETIC.BR (2020). Tic domicÍlios 2019. https://cetic.br/media/analises/tic_domicilios_ 2019_coletiva_imprensa.pdf.

INEP (2020). Senso da educação superior 2019. https://download.inep.gov.br/ educacao_superior/censo_superior/documentos/2020/Apresentacao_Censo_da_

Educacao_Superior_2019.pdf.

Milson, A. L. S., Ribeiro, I. M. C. D., Andrade, I. A., Gonçalves, J. M. M., Laboissiere, L. M., Ferreira1, M. D., Dalip, D. H., Brandão, M. A., and Moro, M. M. (2020). Elas na Ciência: Website com Jogos para Divulgar Personalidades Femininas. 2020: Anais do XIV WIT, 14:10-19.

Oliveira, L. C., Castelini, P., Leite, P. d. S., Almeida, L. D. A., and Amaral, M. A. (2019). "personalities": a participatory approach for gender discussion. Americas Conference on Information Systems (AMCIS).

Rabin, S. (2009.). Introduction to game development. Game development series. Charles River Media, Course Technology, Boston, MA, 2nd edition.

UNESCO (2018). Decifrar o código: educação de meninas e mulheres em ciências, tecnologia, engenharia e matemática (stem). https://unesdoc.unesco.org/ark:/48223/ pf0000264691. 